\title{
Aparelhos de apoio fretado de neoprene: uma revisão
}

\section{Elastomeric bearings with steel plates reinforced: A review}

\section{Aparatos de apoyo fletado de neopreno: una revisión}

\section{Appareils d'appui en élastomère fretté: une révision}

Rian de Oliveira Lan iD rlan@hotmail.com.br Universidade Candido Mendes - UCAM

\section{Resumo}

Este trabalho tem como objetivo tecer considerações sobre os aparelhos de apoio fretado de neoprene. São abordadas as vantagens, as limitações, as metodologias para o seu dimensionamento, as principais patologias e os serviços de manutenção e substituição desses dispositivos. Verifica-se que, para aperfeiçoar o conjunto sistematizado e buscar o domínio do conhecimento sobre apoios em elastômero, são necessários estudos árduos a respeito: de sua fabricação; dos componentes químicos constituintes; do funcionamento das chapas fretantes; das curvas geométricas de vulcanização e de seus respectivos ensaios de qualidade; do ensaio de compressão com força horizontal; de seu posicionamento na obra; bem como de uma norma brasileira específica para o dimensionamento desses dispositivos.

Palavras-chave: Aparelhos de apoio elastoméricos. Concreto armado e protendido. Pontes, viadutos, passarelas e estruturas.

\begin{abstract}
This work aims to weave some considerations on the elastomeric bearings with steel plate reinforced. It deals with the advantages, limitations, methodologies to be used for the sizing, main pathologies, and the maintenance and replacement of these devices. It turns out that to improve the systematic joint and find the domain of the knowledge in the elastomeric bearings, arduous studies are needed regarding the manufacturing process of the components, chemical constituents, the operation of the steel plates, geometric curves of the vulcanization, the respective tests for the quality, the testing of the compression strength of the horizontal, their placement in the work, as well as a Brazilian standard specific for the sizing of these devices.
\end{abstract}

Keywords: Elastomeric bearings. Reinforced concrete and prestressed. Bridges, viaducts, catwalks and structures.

\section{Resumen}

Este trabajo tiene el objetivo de formular consideraciones sobre los apoyos fletados de neopreno. Son tratadas las ventajas, las limitaciones, las metodologías para su dimensionamiento, las principales patologías y los servicios de manutención y sustitución de estos dispositivos. Se verifica que, para perfeccionar el conjunto sistematizado y buscar el dominio del conocimiento sobre soporte en elastómero, son necesarios laboriosos estudios al respecto: de su fabricación; de los componentes químicos constituyentes; del funcionamiento de las placas fletadas; de las curvas geométricas de vulcanización y de sus respectivos ensayos de calidad; del ensayo de compresión con fuerza horizontal; de su posicionamiento en la obra; y también de una norma brasileña específica para el dimensionamiento de estos dispositivos.

Palabras-clave: Aparatos de apoyo elastoméricos. Hormigón armado y pretensado. Puentes, viaductos, pasarelas y estructuras. 


\begin{abstract}
Résumé
Cet article a comme objectif des réflexions sur les appareils d'appui en élastomère fretté. Les avantages, les limites, les méthodes de dimensionnement, les principales pathologies, ainsi que les services de maintenance et de remplacement de ces appareils sont abordés. Il est vérifié que, pour améliorer l'ensemble systématisé et rechercher la maîtrise des connaissances sur les appuis élastomères, des études ardues sont nécessaires concernant: leur fabrication; leurs composants chimiques constitutifs; le fonctionnement des plaques d'affrètement; les courbes géométriques de vulcanisation et leurs tests respectifs de qualité; l'essai de compression des contraintes de traction horizontales; leur positionnement dans le chantier; ainsi qu'une norme brésilienne spécifique pour le dimensionnement de ces appareils.
\end{abstract}

Mots-clés: Appareils d'appui en élastomère. Béton armé et précontraint. Ponts, viaducs, passerelles et structures.

\title{
Introdução
}

O aparelho de apoio fretado de neoprene é um elemento estrutural absorvedor dos momentos fletores do vínculo superestrutura e meso ou infraestrutura. Sua vinculação é semelhante a uma rótula, havendo a união entre duas barras de uma estrutura em que não há transferência de momento fletor, donde considera-se liberdade absoluta de rotação em meio de uma e outra barra, transmitindo apenas esforços normais (axiais) e cortantes (transversais) (THOMAZ; CARNEIRO; SARAIVA, 2014). Esse dispositivo tem como composição um elastômero incorporado com chapas de aço intercaladas com suas camadas. Por meio da vulcanização, as camadas do elastômero se aderem quimicamente às chapas de aço, contendo módulos de deformação transversal e longitudinal moderados, alta resistência à compressão e alta resistência a intempéries. Por conta da alta deformabilidade transversal e longitudinal, acondicionam movimentos de translação, seja qual for a direção e movimentos rotacionais ao redor de qualquer eixo por deformação elástica, transferindo de um elemento estrutural a outro as cargas de projeto e absorvendo os deslocamentos em operação, tendo entre a superestrutura e a meso ou infraestrutura uma articulação elástica (REIS et al., 2018). São peculiares em três tipos:

- Aparelho de apoio fretado simples de neoprene: constituído por bloco fretado de neoprene sem complemento de superfícies de deslizamento ou bloqueio, podendo conter chapas de aço externas que possibilitam a união adequada às mesas de assentamento e podendo ser fixados à estrutura, por ancoragem ou colagem, por meio de pinos e parafusos. Tomam para si deslocamentos longitudinal e transversal, curtos deslocamentos verticais e forças horizontais, conforme sentidos longitudinal e transversal, como também esforços normais, sem transferir quaisquer momentos fletores (VIEIRA, 2013).

- Aparelho de apoio fretado fixo de neoprene: integrado com dispositivo de bloqueio capaz de impedir os deslocamentos horizontais. É constituído por chapas de ancoragem exteriores com dimensões maiores que o bloco de neoprene fretado e possui um dente em sua chapa inferior que, ao endentar na chapa superior, possibilita o bloqueio dos movimentos de translação. Esse dispositivo opera com curtos deslocamentos verticais, capacidade de rotacionar ao redor dos três eixos, transferência do esforço normal e sem transmissão de momentos fletores. (VIEIRA, 2013).

- Aparelho de apoio fretado de neoprene com superfície de deslizamento com ou sem guia: apropriado quando se busca livre deslocamento horizontal ou exclusivamente em uma das direções - longitudinal ou transversal -, sendo fixadas superfícies de deslizamento e guiamento. A utilização de folhas de politetrafluoretileno (PTFE) aderidas ao bloco fretado de neoprene permite fixar superfícies metálicas, garantindo deslocamentos relevantes. As superfícies que possuem guiamento possibilitam deslocamentos somente em uma das direções horizontais (unidirecionais), e as que não possuem guiamento possibilitam deslocamentos em ambas as direções (multidirecionais). Esse dispositivo opera 
com curtos deslocamentos verticais, capacidade de rotacionar ao redor dos três eixos, transferência do esforço normal e sem transmissão de momentos fletores (VIEIRA, 2013).

O aparelho de apoio fretado de neoprene simplifica o uso de seguimento contínuo de estruturas executando a ligação sobre os mesmos e reduzindo juntas de dilatação. É propício ao uso de abas empenhadas em garantir o nivelamento para a adequada operação da estrutura. São utilizáveis mesmo apresentando deformações naturais. Com mais de 40 anos em uso podem suportar o triplo da carga para o qual foram dimensionados. Quando apoiam os dentes Gerber, distribuem de modo uniforme o esforço cortante. Mesmo operando de forma incorreta, com os movimentos horizontais impedidos, teflon sacrificado, aparência desgastada e distorcido, o aparelho de apoio fretado deslizante de neoprene é capaz de operar em seu devido lugar. Em determinados casos, quando as estruturas acidentadas portam aparelhos de apoio fretado deslizante de neoprene, podem ser substituídos por aparelhos de apoio fretado simples de neoprene.

Este trabalho tem como objetivo, por meio de uma revisão de literatura, tecer considerações sobre os aparelhos de apoio fretado de neoprene.

\section{Definição e importância}

Os aparelhos de apoio fretados são feitos de borracha sintética durável, conhecida comercialmente como neoprene, seu nome químico é poli-2-clorobutadieno (CARDOSO; LIMA, 2016). Esse elastômero apresenta características de extensibilidade e de recuperação elástica iguais às da borracha natural, com um elevado diferencial de resistência ao envelhecimento, politetrafluoretileno (PTFE) com propriedades antiaderentes, impermeabilidade, baixo coeficiente de atrito, resistência as variações de temperatura, umidade e corrosão, capacidade de se deixar usinar e atóxico (CARDOSO; LIMA, 2016).

O aparelho de apoio fretado de neoprene é formado por uma ou mais camadas primárias de elastômero, cobrimento e chapas fretantes, contendo ou não politetrafluoretileno (PTFE). É um elemento de interação entre peças estruturais em obras de arte que possuem ligação apoiada com grandes portes e extensões (Fig. 1). Possui comportamento não linear (SILVA; CAMPOS; FILHO, 2017), sendo de fundamental importância à prevenção de patologias provenientes das reações e de movimentos naturais previstos em projetos da superestrutura à mesoestrutura, suportando a transmissão de forças dinâmicas e vibrações que podem acarretar instabilidade ou destruição da ponte (FERNANDES; CORREIA, 2017).

Figura 1 - Elemento de interação superestrutura-mesoestrutura.

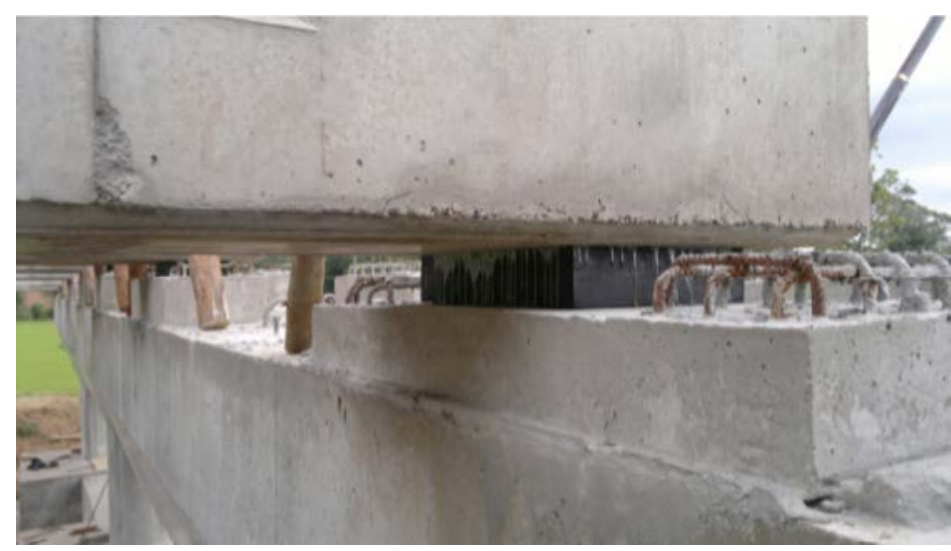

Fonte: Adaptado de Nuernberg e Silva, 2013.

O uso do dispositivo proporciona minorar grandeza total da estrutura, otimizando o corte do tabuleiro e a cabeça dos pilares. Os aparelhos mais recentes protegem ainda das ações sísmicas, dissipando energia (FERNANDES; CORREIA, 2017). 
A alternância das placas de neoprene vulcanizadas com as chapas de aço faz com que o aço tracionado contenha o escoamento lateral do neoprene comprimido, elevando as tensões admissíveis no aparelho de apoio devido à habilidade física de aderência ocasionada pela vulcanização simultânea. A eficiência na adesão elastômero-aço deve-se, primeiro, ao preparo das chapas fretantes com jatos de areia e colantes químicos antes da vulcanização (VIVAN, 2015).

Esse "sanduíche" resulta em baixos valores de módulos de elasticidade transversal - parâmetro com maior importância no dimensionamento e na classificação dos dispositivos (CARDOSO; LIMA, 2016) - e longitudinal, consequentemente, garante maior deformabilidade transversal e longitudinal, funcionando como uma articulação elástica e interagindo com mais funcionalidade na estrutura em movimentos de rotação e translação. Os dispositivos proporcionam, nas dimensões usuais, rotações de até $15.10^{-3}$ radianos, ou seja, em torno de $1^{\circ} \mathrm{grau}$ (THOMAZ; CARNEIRO; SARAIVA, 2014). Suas rigidezes são os coeficientes de elasticidade transversal do neoprene e Poisson iguais a $10 \mathrm{kgf} / \mathrm{cm}^{2}$, ou $0,98 \mathrm{Mpa} \mathrm{e} 0,5$, respectivamente, e dureza Shore A60 com tolerância de \pm 5 (ANDRADE; TRAUTWEIN; BITTENCOURT, 2013). pontos. Essa classe de dureza do elastômero é usada para classificação do material (CARDOSO; LIMA, 2016).

A fabricação do aparelho de apoio fretado de neoprene está condicionada a assegurar o paralelismo das chapas de aço, como também a resistência na ligação elastômero-aço quanto ao requisito de distorção até $\operatorname{tg}$ = 2, como preconiza a NBR 19783/2015 (VIVAN, 2015). Atualmente, são dimensionados para uma tensão de compressão máxima de $10 \mathrm{MPa}$, mas anteriormente era considerada uma tensão de $15 \mathrm{MPa}$. Aparelhos dimensionados para essa tensão são encontrados na Ponte Rio-Niterói (SIQUEIRA; SILVA, 2009).

A Euronorma EN 1337 é dividida em 11 partes, sendo a norma mais completa e atual. O projeto do aparelho de apoio fretado de neoprene é simples, baseado nas definições dos estados limites, principalmente do estado limite último - perda de equilíbrio estático, colapso interno da estrutura ou de seus elementos e ligações, colapso ou deformações excessivas das estruturas e ruína por fadiga - correlaciona com as normas usadas em projetos de estruturas. A análise da qualidade é feita por meio de testes em protótipos e rotina: executando antes do começo da produção ou quando há alteração no projeto do aparelho e executando ao longo da fabricação dos dispositivos, sobretudo nas matérias-primas e componentes (VIVAN, 2015).

\section{Vantagens}

Os aparelhos de apoio fretado de neoprene têm em si uma elevada resistência a intempéries, sendo uma característica relevante frente aos demais aparelhos, dispensando manutenção periódica. $O$ dispositivo atende às expectativas mesmo obtendo fabricação com materiais de baixa qualidade (MACHADO; SARTORTI, 2010).

Para uma correta instalação dos aparelhos de apoio fretado de neoprene, em sua grande maioria no Brasil, é fundamental considerar as seguintes disposições (SIQUEIRA, 2012):

- Tanto o centro de gravidade do dispositivo de policloropreno quanto o centro de gravidade do berço de assentamento devem ser equivalentes;

- O menor comprimento do dispositivo elástico deve ser posto na direção longitudinal da viga;

- Evitar superfícies oblíquas entre o dispositivo e a viga ou berço de assentamento.

Se o aparelho de apoio fretado de neoprene não possuir anomalia visível, somente deformações naturais oriundas da utilização e sujeira, ainda está adequado à utilização. Conforme a Figura 2, pode ser observado que o dispositivo do encontro E1 não apresenta anomalia em seu perímetro, somente deformações naturais devido à utilização e sujeira. Os demais aparelhos de apoio fretado de neoprene da ponte ferroviária na estrada do ferro Carajás estão em condições semelhantes à do aparelho de apoio do encontro E1, portanto ainda adequados para utilização (SANTOS; OLIVEIRA, 2012). 
Figura 2 - Aparelho de apoio fretado de neoprene situado no encontro E1.

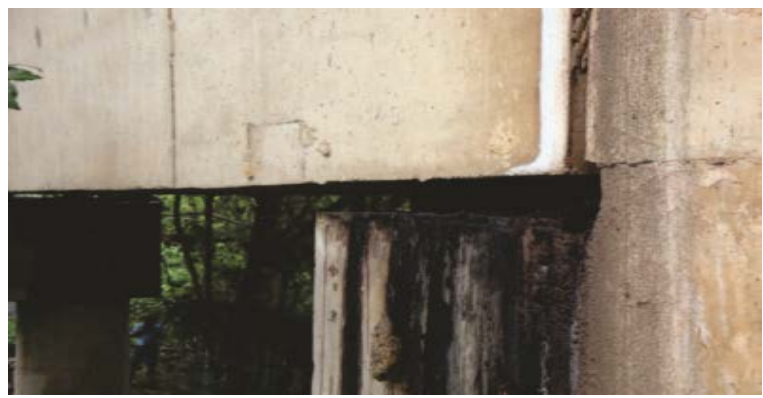

Fonte: Adaptado de Santos e Oliveira, 2012.

Está passiva a utilização de abas nos aparelhos de apoio fretado de neoprene em obras que apresentam, entre a estrutura e o apoio, variabilidades em inclinações, superelevação e diferença de cotas entre outros apoios, tanto de uma mesma linha de apoio como de linhas consecutivas. Essas abas devem ser especificadas no projeto quanto a sua inclinação, servindo de molde para o preenchimento de graute ou resina, proporcionando paralelismo, horizontalidade e planicidade, garantindo inclinação exata nos apoios e correta distribuição linear das cargas (NUERNBERG; SILVA, 2013).

Para reduzir reações horizontais, visando melhor mobilidade horizontal, é preciso revesti-lo com folha de teflon, que é uma resina que possui baixos coeficientes de atrito mesmo sofrendo alta pressão. A folha de teflon é aderida a uma chapa de aço inoxidável polida até o espelhamento da superfície (Fig. 3), e essa chapa é fixada na superestrutura, tornando-se uma articulação elástica deslizante comumente chamada de Neoflon (VIVAN, 2015).

Figura 3 - Aparelho de apoio fretado de neoprene situado no encontro $\mathrm{E} 1$.

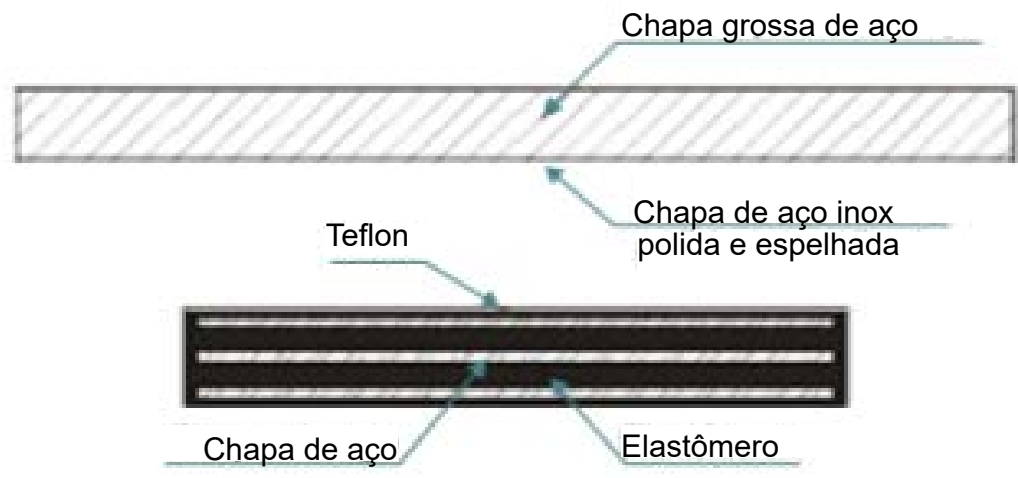

Fonte: Adaptado de Vivan, 2015.

No caso do acidente do viaduto T5 da Marginal Pinheiros, devido ao trecho extenso, o segmento encolhe muito no decorrer dos primeiros anos, o equivalente a $13 \mathrm{~cm}$ em torno de 10 anos, por retração e fluência (decorrente da idade do concreto), como ilustra a Fig. 4. Foi considerada como uma das causas a hipótese natural do escorregamento da lingueta - alongamento da transversina de apoio, do fundo do caixão até a cabeça do pilar - sobre o teflon do dispositivo (Fig. 5), visto que a lingueta é um tipo de vínculo preocupante por perda de capacidade portante e da dificuldade para realização do macaqueamento, devido ao atrito com a lingueta vizinha. Antes da obtenção do projeto da obra de arte, deduziu-se que o aparelho de apoio recebia uma carga $V$ com excentricidade (e) de $10 \mathrm{~cm}$ (Fig. 6) e força horizontal de atrito de 5 a $10 \%$. Essa dedução passou com folga. Após obtenção do projeto, constatou-se que a posição da lingueta foi posta com excentricidade de $5 \mathrm{~cm}$ no sentido oposto ao movimento, tornando a verificação ainda mais folgada (FANTE et al., 2019). 
Figura 4 - Viaduto T5 da Marginal Pinheiros.

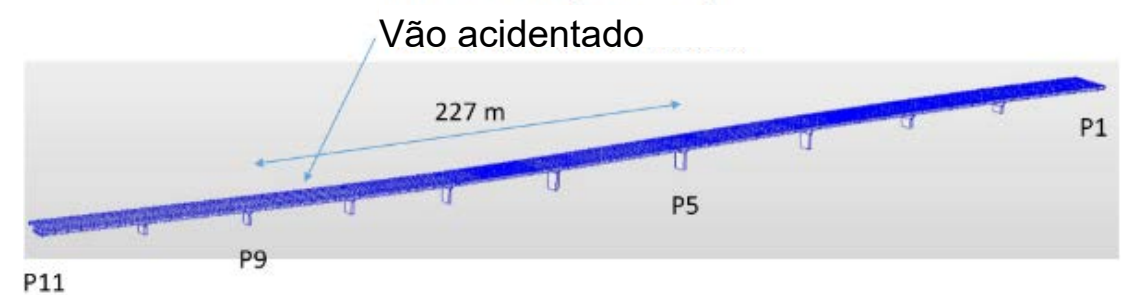

Fonte: Adaptado de Fante et al., 2019.

Figura 5 - "Escorregamento" da lingueta.

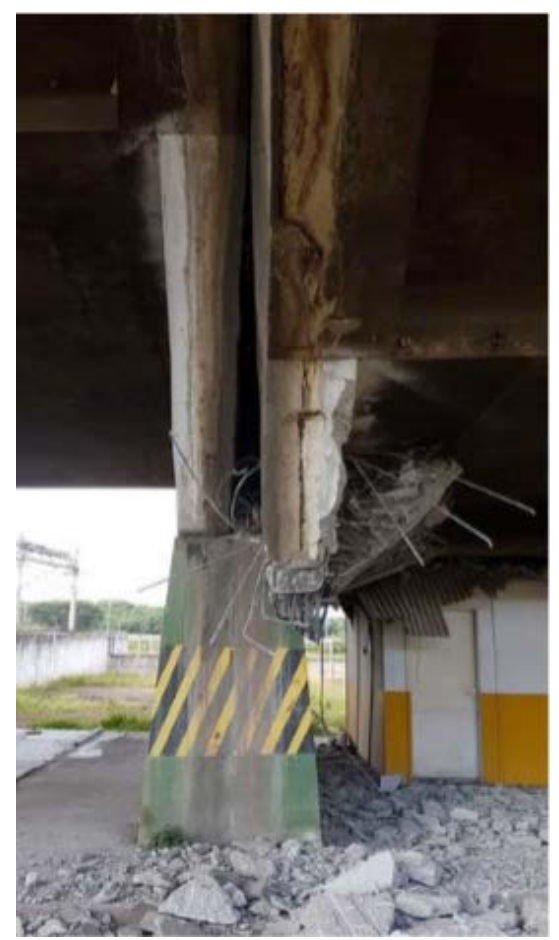

Fonte: Adaptado de Fante et al., 2019.
Figura 6 - Carga $\vee$ excêntrica

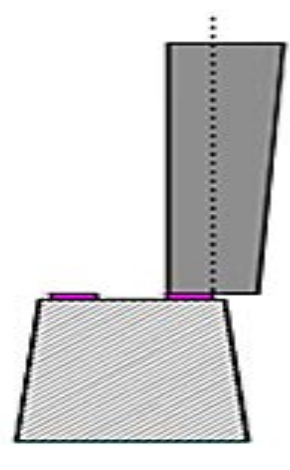

$$
\mathrm{e}=10 \mathrm{~cm}
$$

Fonte: Adaptado de Fante et al., 2019.

O relato justificou a hipótese de o dispositivo estar operando com impedimento dos movimentos horizontais (Fig. 7), constatando que, mesmo o viaduto operando de forma incorreta, os aparelhos de apoio fretado de neoprene com teflon estando distorcidos na ordem de 1x1 (Fig. 8), com o teflon sacrificado e a aparência desgastada, mas o dispositivo estava em seu devido lugar, sendo capaz de permitir o deslizamento com quase 40 anos de idade (Fig. 9). A hipótese de os aparelhos estarem deixando de permitir o deslizamento como uma possível causa do escorregamento da lingueta através do teflon foi descartada (FANTE et al., 2019). 
Figura 7 - Impedimento dos movimentos horizontais.

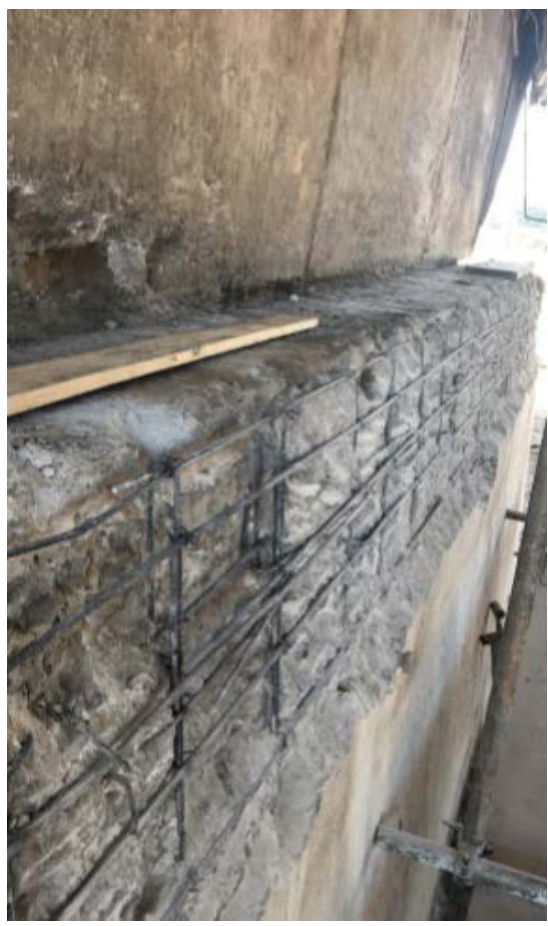

Fonte: Adaptado de Fante, et al., 2019.

Figura 8 - Dispositivo distorcido.

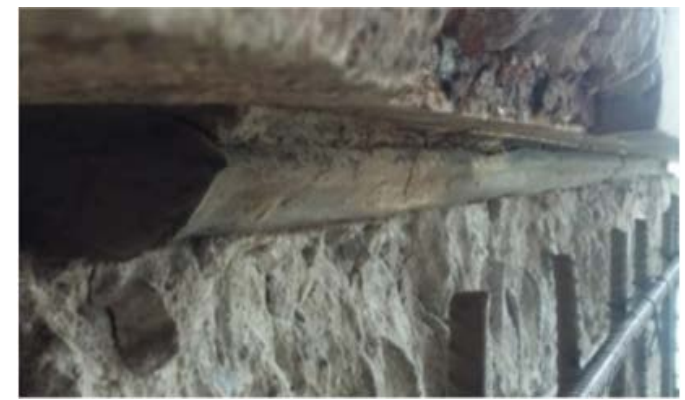

Fonte: Adaptado de Fante, et al., 2019.
Figura 9 - Teflon sacrificado e aparência desgastada

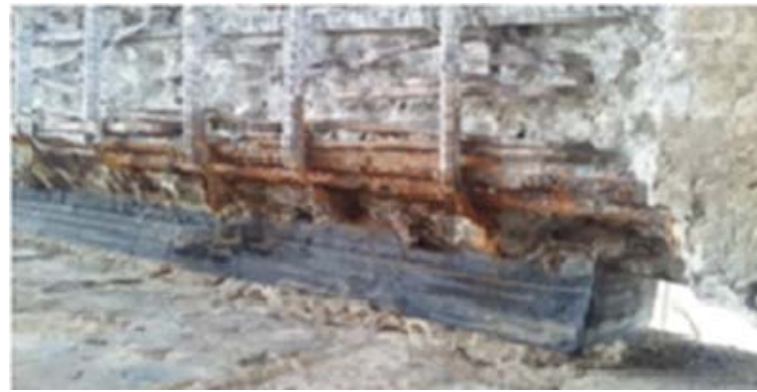

Fonte: Adaptado de Fante, et al., 2019.

Os apoios deslizantes foram substituídos por apoios normais, já que a estrutura passou por toda a retração e fluência, que também são capazes de permitir deslocamentos ocasionados por temperatura (FANTE et al., 2019).

O aparelho de apoio fretado de neoprene viabiliza a otimização de uma estrutura, como o dente Gerber, que é uma rótula em que ocorre o predomínio de esforço cortante $(\mathrm{Q})$ sobre o esforço normal $(\mathrm{N})$, conforme Fig. 10. Essa rótula apresenta duas funções (THOMAZ; CARNEIRO; SARAIVA, 2014):

- Estrutural: Permite deformações, prevenindo a manifestação de esforços internos relacionados a recalques diferenciais nos apoios;

- Construtiva: Admite o lançamento de vigas pré-moldadas em vãos acima de leitos de rio ou de difícil acesso. 
A utilização do dente Gerber admite ocorrer deformações axiais das vigas resultantes da retração, da deformação prolongada (em vigas de concreto protendido) e de deformações térmicas, mantendo adequadamente a estabilidade e tornando a estrutura isostática (THOMAZ; CARNEIRO; SARAIVA, 2014).

Figura 10 - Dente

Gerber.
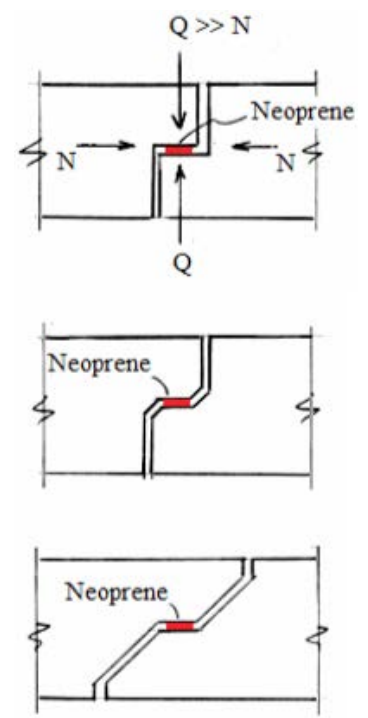

Fonte: Adaptado de Thomaz, Carneiro e Saraiva, 2014.

De acordo com o estudo de viga ensaiada mediante um extensômetro mecânico, foi observado a curva entre deformação de encurtamento e uma carga $\mathrm{P}$ de cada neoprene. $\mathrm{O}$ limite da deformação de encurtamento só pôde ser medido até a carga de 120 kN, referente a 3 dispositivos na estrutura (Fig. 11). Após 120 kN não houve possibilidade de fazer a leitura por meio do extensômetro, pois alguns pinos metálicos soltaram da viga (THOMAZ; CARNEIRO; SARAIVA, 2014).

Figura 11 - Estudo de viga ensaiada.

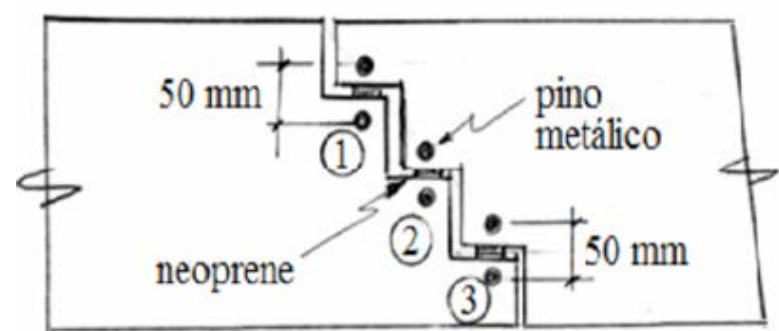

Fonte: Adaptado de Thomaz, Carneiro e Saraiva, 2014.
Figura 12 - Curva de deformações.

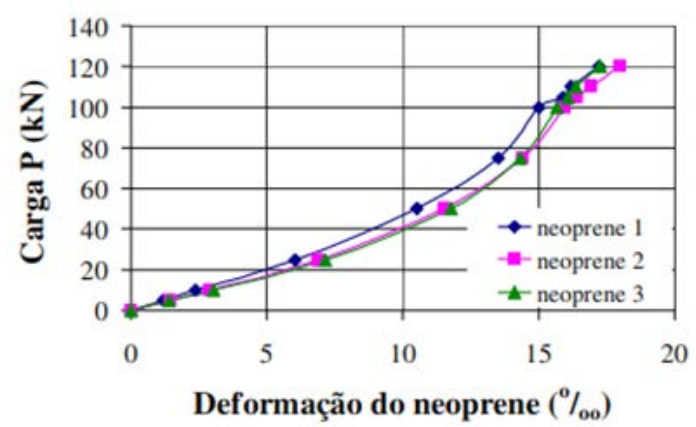

Fonte: Adaptado de Thomaz, Carneiro e Saraiva, 2014.

Observa-se que a curva das deformações (Figura 12) de cada dispositivo estão próximas, podendo entender que a distribuição de esforço cortante ocorre de modo uniforme entre os três aparelhos de apoios fretado de neoprene do dente (THOMAZ; CARNEIRO; SARAIVA, 2014).

Um estudo com objetivo de esclarecer que ensaios à compressão simples em dispositivos com escalas naturais apresentavam desempenhos superiores aos de escala reduzida, conforme determinação da extinta NBR 9783/1987, como os retirados das estruturas da Ponte Rio-Niterói e da demolição do Elevado da Avenida Perimetral, porém produzidos pela mesma empresa, mostrou que aparelhos que não apresentam anomalias decorrentes do tempo em uso, como os do Elevado da Avenida Perimetral, com 37 anos de uso, tendem a não alterar sua estrutura física na aplicação gradativa de cargas maiores que $15 \mathrm{MPa}$. Além disso, que os 
dispositivos que apresentavam anomalias, como os da Ponte Rio-Niterói, com a aplicação gradativa das cargas, as anomalias progridem e que, ainda assim, se tornam vantajosos, pois suportam cargas para o qual foram dimensionados (SIQUEIRA; SILVA, 2009).

Em síntese, os resultados dos ensaios de campo e laboratório foram:

- Aparelho de apoio 1 (campo) apresentava bojamento e fissura generalizada; resistiu à carga de 15 $\mathrm{MPa}$ e até $45 \mathrm{MPa}$ seu comportamento foi normal; houve acréscimos dos bojamentos existentes e o surgimento de novos bojamentos; não configuraram descontinuidades estruturais do dispositivo. Em $48 \mathrm{MPa}$ houve rompimento vertical, em contrapartida não houve esmagamento. Suportou o triplo da carga para o qual foi dimensionado, com 42 anos de uso.

- Aparelho de apoio 2 (campo) apresentava bojamento com fissura generalizada; desempenho normal até $10 \mathrm{MPa}$; aumento dos bojamentos já existentes de 15 a $40 \mathrm{MPa}$; Em $45 \mathrm{MPa}$ houve rasgamento da anomalia existente, sem ocorrer o esmagamento. Dispositivo atente às condições normais de tensão de projeto.

- Aparelho de apoio 3 (campo) não apresentava anomalias e também não apresentou alteração física durante a aplicação da carga.

- Aparelho de apoio 4 (campo) apresentava fissuras em uma das faces e encontro entre faces com rompimentos; já existia lesões alojadas em seu estado original; a anomalia não se alterou durante a aplicação da carga de $15 \mathrm{MPa}$; Daí em diante, até $40 \mathrm{Mpa}$, as lesões aumentaram sem ocorrer esmagamento, operando em condições de projeto.

- Aparelho de apoio 5 (campo) apresentava rasgamento vertical em uma de suas faces e suas anomalias não se alteraram até $10 \mathrm{MPa}$; com $15 \mathrm{MPa}$ as anomalias aumentaram sem surgir novas lesões; em $20 \mathrm{MPa}$ ocorreu estado de fissuração generalizada; de 25 a $45 \mathrm{MPa}$ novas lesões se manifestaram, mas sem ocorrer o rompimento do dispositivo; em $50 \mathrm{MPa}$ a chapa fretante rompeu, mesmo com a estrutura física alterada, funcionou à carga de projeto. O rompimento da chapa fretante não foi novidade, pois sua espessura era de $0,7 \mathrm{~mm}$, sendo que a extinta NBR 9783/1987 exigia o mínimo de $2 \mathrm{~mm}$ de espessura para chapas fretantes quando a espessura da camada elementar era menor ou igual a $5 \mathrm{~mm}$.

- Aparelho de apoio 6 (laboratório) não apresentou alteração física durante a aplicação da carga. No estágio de $60 \mathrm{MPa}$ houve rasgamento do elastômero e o descolamento borracha-aço.

- Aparelhos de apoio 7 e 8 (laboratório) possuíam uma série de anomalias antes de serem submetidos ao ensaio. Detectou-se progressão dos defeitos de tensão correspondente a $15 \mathrm{MPa}$, seguindo-se a mesma diretriz nas cargas subsequentes de 30, 40 e $60 \mathrm{MPa}$.

De acordo com a NBR 19783/2015, em dispositivos submetidos a testes de compressão simples nos níveis de $40 \mathrm{MPa}$ não pode haver o rasgamento do elastômero e em $60 \mathrm{MPa}$ não pode haver descolagem na união elastômero-aço, como também as chapas de aço não devem escoar ou apresentar ruptura (SIQUEIRA; SILVA, 2009).

\section{Desvantagens}

Antes da extinta NBR 9783/1987 entrar em vigor, a concepção dos dispositivos era evitada por engenheiros estruturais, temendo que a fabricação não atingisse a qualidade apropriada. Por exemplo, quando a pista ascendente da via Imigrantes entrou em serviço, foi necessária a substituição de grande quantidade dos dispositivos. Esse fato resultou em buscar dados de ensaios realizados em 59 apoios de diferentes obras, como Rodovia dos Imigrantes e Ponte Rio-Niterói, e confrontar com dados previstos em normas estrangeiras, com o propósito de adquirir contribuições para elaboração de uma futura norma brasileira. Esses fatos garantiram significativas melhorias em fabricação e projeto dos aparelhos de apoio fretado de neoprene (VIVAN, 2015). 
A superestrutura em concreto protendido da ponte sobre o Canal do Moxotó, com fundações concretadas sobre rocha, com pilares altos e esbeltos com geometria hidrodinâmica em falsa elipse, para não ceder à correnteza do canal, teve seus dispositivos reprovados devido aos ensaios realizados obterem coeficiente de atrito dos apoios extremos deslizantes de $8 \%$. A norma preconiza coeficiente de atrito dos aparelhos deslizantes deve ser $\leq 4 \%$. Além do mais, os dispositivos foram todos dimensionados novamente devido à falta de armadura de ligação entre eles no topo dos pilares e, ao acrescentar a quantidade de dispositivos sob as transversinas, não existia armadura de fretagem localizada sob o novo aparelho. Foi estabelecido para o aço inox grau de polimento resultando em uma face espelhada. Com o exposto, os aparelhos tiveram sua fabricação, seus ensaios aprovados, atingindo coeficiente de atrito de $2 \%$ nos aparelhos de apoio fretado deslizante de neoprene (VIVAN, 2015).

Os aparelhos de apoio fretado de neoprene mal posicionados operam incorretamente. Mesmo atingindo fabricação esmerada e atendendo aos padrões normativos, a instalação incorreta ocasiona a expulsão do aparelho de apoio do berço, conforme Fig. 13 (SIQUEIRA, 2012). O dispositivo que está sob funcionamento de rotação induzida por cargas aplicadas na superestrutura em superfície com diferença de nível (Fig. 14), como em um tabuleiro com declive - compensação da força centrífuga -, encontro, calço ou berço desnivelados, e também detritos de concreto (Fig. 15), resultam em uma tensão de rotação adicional no apoio, prejudicando a estrutura por não distribuir as cargas de modo uniforme (NUERNBERG; SILVA, 2013).

Figura 13 - Expulsão do dispositivo de seu berço

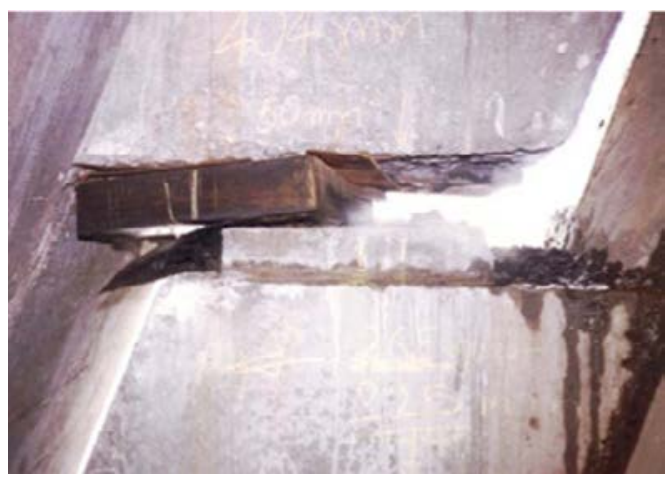

Fonte: Adaptado Siqueira e Silva, 2009.
Figura 14 - Superfície com diferença de nível.

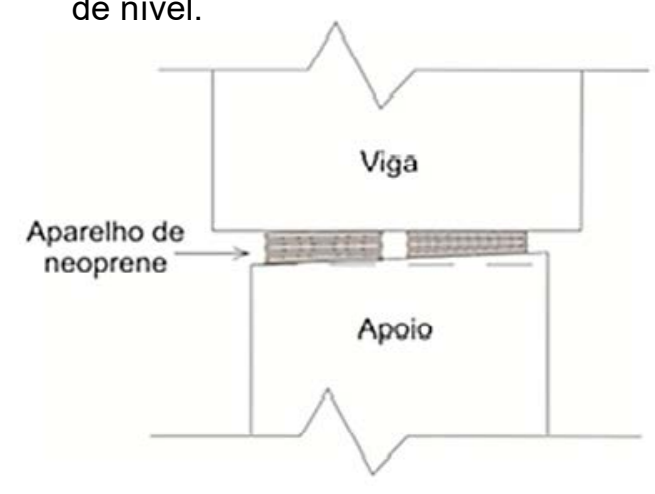

Fonte: Adaptado de Nuernberg e Silva, 2013.

Figura 15 - Detritos de concreto.

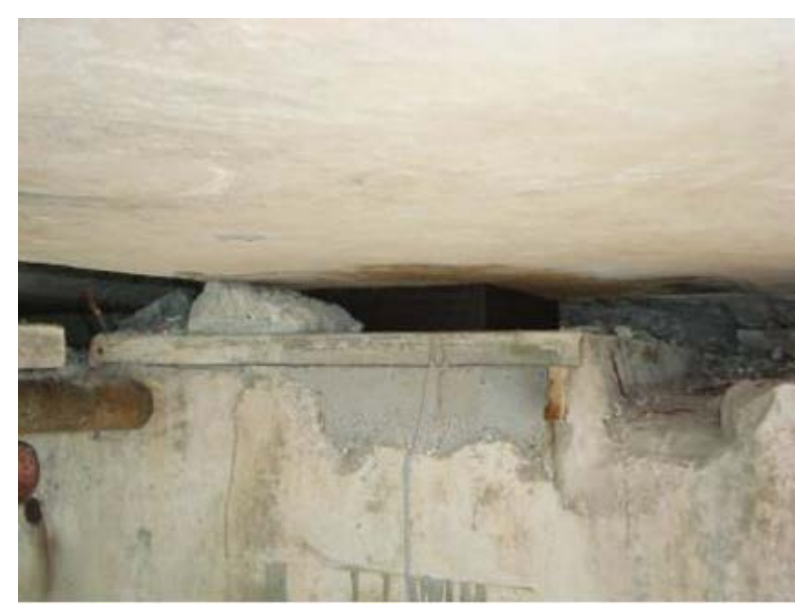

Fonte: Adaptado de Gomes, Monteiro e Vitório, 2017. 
A falta de paralelismo das superfícies do dispositivo e do fundo da viga pode incentivar uma má distribuição do carregamento, exigindo mais de uma determinada parte do apoio do que do restante, possibilitando desenvolvimento de bojamentos laterais das camadas individuais de elastômero, surgindo fissuras ou rasgamentos (SIQUEIRA, 2012).

Com a progressão do uso de vigas pré-moldadas e protendidas mais esbeltas, fadadas a atravessar longos vãos em obras de arte, elas são simplesmente assentadas sobre aparelhos de apoio fretado de neoprene quando estão em estágio de transição ou serviço. Devido a sua flexibilidade, o dispositivo pode ocasionar colapso da estrutura por meio de instabilidade lateral quando em estágio de pré-serviço no momento em que a estrutura não tem vínculo que impossibilite o tombamento da viga (CARDOSO; LIMA,2016).

Quando os dispositivos não desempenham a sua função, ocasionam fissuras e deslocamentos nas extremidades dos apoios da estrutura (Fig. 16, 17 e 18), conforme a Figura 16, um exemplo de apoio isostático comumente chamado de dente de articulação (SANTOS et al., 2017).

Figura 16 - Fissuras nas extremidades dos apoios da estrutura.

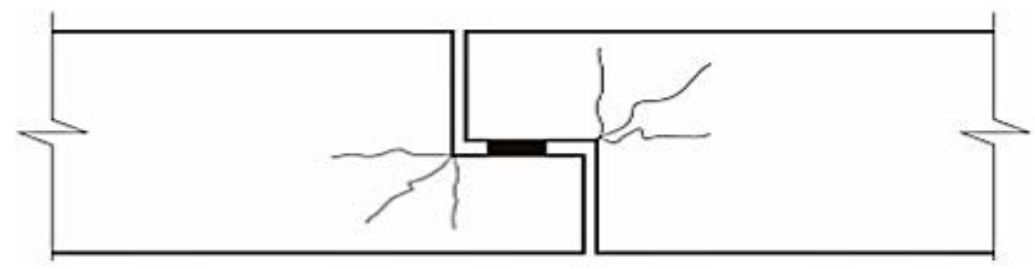

Fonte: Adaptado de Santos et al., 2017.

Figura 17 - Fissura e deslocamento na extremidade do apoio.

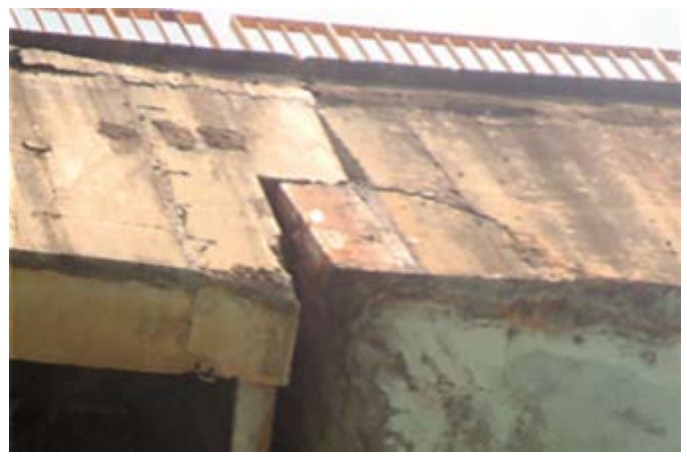

Fonte: Adaptado de Santos et al., 2017.
Figura 18 - Deslocamento na extremidade do apoio.

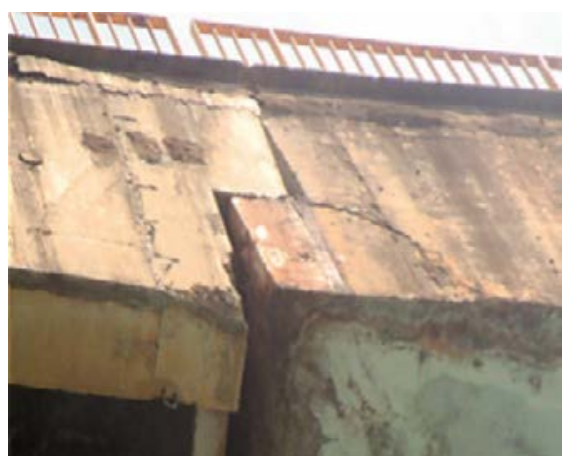

Fonte: Adaptado de Santos et al., 2017.

Nenhuma estrutura é perene, no entanto, sua vida útil global é maior do que a vida útil do dispositivo, decorrendo de reparação ou substituição do mesmo ao longo da operação da obra (BRANCO; PAULO, 2012).

\section{Metodologias para dimensionamento}

O dimensionamento do aparelho de apoio fretado de neoprene pode se basear por metodologias de diferentes autores, como Basler e Witta (1967), DIN 4141-14 (1985), Pfeil (1988), EN 1337 (2005), Marchetti (2007), e por seus próprios fabricantes - levando em consideração possíveis falhas na fabricação e na aplicação -, demonstrando solução diferente para cálculos de flambagem (NUERNBERG; SILVA, 2013). 


\section{Principais patologias}

As patologias do dispositivo aparecem regularmente expostas em seu perímetro (SIQUEIRA; SILVA, 2009). As causas determinantes da inutilidade precipitada do aparelho de apoio são causas endógenas e exógenas, como assentamento irregular em superfícies deformadas, apoio agindo com deslocamentos, rotações e cargas maiores do que os previstos, agressividade imprevista do meio ambiente em que está situado, ataques por produtos químicos, redução de vida útil e mau assentamento no berço (DIÓGENES et al., 2014).

Um estudo feito em uma ponte sobre a Lagoa de Roteiro, em Alagoas, com quase 20 anos de existência, com traçado horizontal retilíneo, perpendicular ao fluxo da lagoa, sistema construtivo em concreto armado e protendido, transferindo os esforços da superestrutura para mesoestrutura através de aparelhos de apoio fretado de neoprene, apresentou dispositivos dos encontros desgastados, com medidas originais alteradas, bem como desenvolvimento de vegetação em alguns deles (SILVA et al., 2018).

Estruturas de concreto estão suscetíveis a deformações adicionais, por esforços solicitantes externos indiretos, de origem térmica, caso a variação exata não seja assumida em projeto. A deformação térmica excessiva altera o volume da peça, dilatando o concreto e elevando as tensões nos aparelhos de apoio fretado de neoprene, excedendo o potencial de deformação do elastômero projetado inicialmente (NUERNBERG; SILVA, 2013).

Em estruturas que possuem sessão longitudinal em rampa excessiva, os dispositivos deformam-se até alcançar seu limite ao aumentar de temperatura, levando ao deslizamento da estrutura, a favor da gravidade, intensificando o deslizamento nos aparelhos de apoio mais baixos. Quando a estrutura contrai devido à redução de temperatura, o deslizamento será maior nos aparelhos de apoio mais altos (NUERNBERG; SILVA, 2013).

Conforme o DNIT, as extensões longitudinais que apresentam rampa, moderada ou nivelada, não serão influenciadas pela gravidade, pois o deslizamento será causado por instabilidade no coeficiente de atrito entre o neoprene com o concreto, anomalias construtivas, oscilação de incidência solar em toda a extensão da peça etc. O "rastejamento" (Figura 19) é consequente do movimento progressivo capaz de deslocar a estrutura em relação à mesoestrutura e infraestrutura. As deformações relativas às variações de temperatura são superiores às projetadas, impossibilitando ao aparelho de apoio fretado de neoprene reter as deformações excessivas (NUERNBERG; SILVA, 2013).

Figura 19 - "Rastejamento" da estrutura.

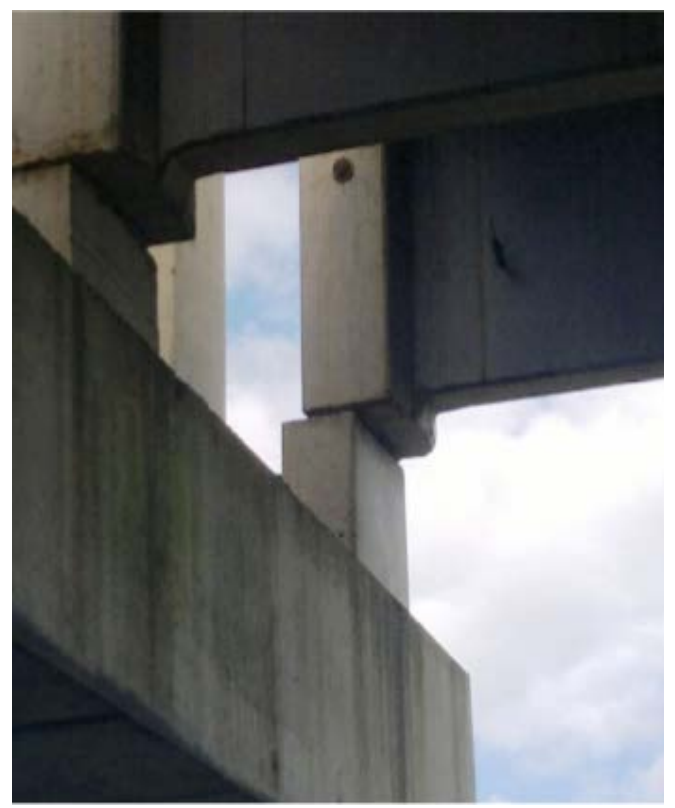

Fonte: Adaptado de Nuernberg e Silva, 2013. 
O fato da estrutura do aparelho de apoio fretado de neoprene estar esmagada e ressecada impede que seja feito reparo, de modo que o seu mau funcionamento pode ocasionar problemas estruturais (Fig. 20), sendo necessário realizar uma inspeção especializada, visto que os danos no aparelho de apoio podem ter sido originados por esforços excessivos da estrutura (SILVA; CAMPOS; SANTOS FILHO, 2017).

Figura 20 - Dispositivo esmagado.

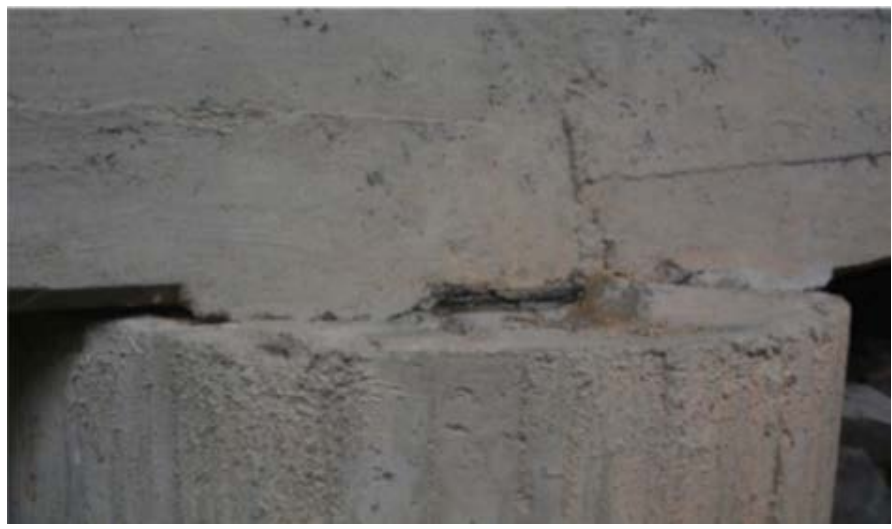

Fonte: Adaptado de Silva, Campos e Santos Filho, 2017

A ausência de detalhamento pertinente à vedação das juntas de dilatação em pontes pode colaborar para uma má execução no projeto e, consequentemente, gerar imperfeições que permitam a infiltração de água, atacando as armaduras e danificando os aparelhos de apoio, conforme a Fig. 21 (DIÓGENES et al., 2014).

Figura 21 - Falhas na junta de dilatação.

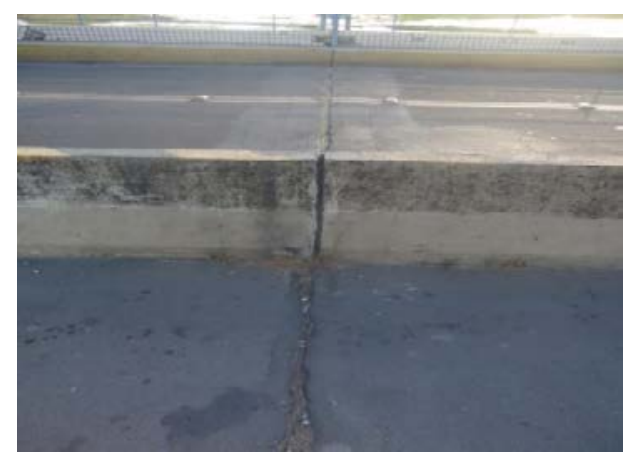

Fonte: Adaptado de Diógenes et al., 2014.

\section{Serviço de manutenção e substituição}

Uma manutenção regular nas pontes visa manter os aspectos financeiros, estruturais, funcionais e de durabilidade em toda a sua vida útil, iniciando a partir do processo de construção, identificando em tempo hábil os danos que venham a surgir para reparar os que evoluem ao longo da vida útil das estruturas (GOMES; MONTEIRO; VITÓRIO, 2017).

Quando não efetuadas as ações de manutenção em tempo ágil, como determinam as inspeções rotineiras, especiais e extraordinárias, os danos consequentemente se agravam, elevando geometricamente os custos de manutenção das regiões danificadas. Ao efetuar as ações pertinentes à manutenção em tempo hábil, a atividade fornecerá subsídios ao planejamento e realização dos trabalhos de manutenção, diminuindo custos com recuperação ou reforço estrutural (GOMES; MONTEIRO; VITÓRIO, 2017).

Como exemplo relevante da falta de manutenção relativa a complicações construtivas em obras de arte com ocorrência no Brasil nos anos 90, especificamente na cidade de São Paulo, a Ponte dos Remédios, 
construída em 1968, próxima de completar 30 anos sem passar por manutenção por negligência, tinha seus aparelhos de apoio danificados, além de problemas construtivos, ocasionando um custo para recuperação de $\mathrm{R} \$ 6,2$ milhões, como também outro custo avaliado em $\mathrm{R} \$ 25$ milhões/dia, pois foi preciso paralisar a rodovia transversal Marginal Tietê, sendo perto de um custo de uma nova ponte (GOMES; MONTEIRO; VITÓRIO, 2017).

Em conformidade com DNIT, os aparelhos de apoio de qualquer material e tipologia devem ser inspecionados de forma que sejam observados sua condição e seu desempenho (SANTOS, et al., 2017).

Aproveitar o aparelho em sua atividade ou substituir dependerá da inspeção e da verificação e dos potenciais comprometimentos da estrutura, destacando a importância em aproveitar o material, uma vez que a troca tem como consequência fatores adicionais, como a interdição da ponte (MACHADO; SARTORTI, 2010).

A realização de manutenção e inspeção não deve exceder um período quinquenal. Devido a campanhas anuais, os aparelhos de apoio fretado fixos e deslizantes de neoprene da Ponte Rio-Niterói foram monitorados recebendo inspeções por ano e a cada cinco anos para acompanhar seu comportamento (SIQUEIRA; SILVA, 2009).

Antes da pesquisa de ensaios à compressão em campo e em laboratório com dispositivos em verdadeira grandeza e em corpos de prova reduzidos, em uso por 42 anos, que tinha em vista constituir parâmetros técnicos de necessidade da substituição com base em dados técnicos experimentais conclusivos, a substituição dos mesmos era uma incógnita, feita de modo empírico (SIQUEIRA; SILVA, 2009).

A monitoração enfatizou que a substituição dos dispositivos somente deve ser feita quando ocasionar defeitos críticos das estruturas que se apoiam no dispositivo ou que suportam o mesmo (SIQUEIRA; SILVA, 2009).

Vale ressaltar que os ensaios referidos na extinta NBR 9783/1987 para recebimento desses dispositivos ponderam a qualidade de dispositivos recémconcebidos, não servindo para controlar qualidade do aparelho de apoio em serviço, levando em conta somente indicadores numéricos como referência (SIQUEIRA; SILVA, 2009).

Constata-se que o comportamento dos apoios que tiveram descarte nos perímetros foram inferiores aos de verdadeira grandeza, apenas os bojamentos comuns oriundos das solicitações impostas. O bojamento não se trata de uma anomalia preocupante que possa acelerar a degradação do dispositivo, no entanto é o sinal de que o material está chegando ao seu estado limite de uso mediante as deformações. Nos ensaios foi mostrado que os desempenhos dos corpos de prova reduzidos tornam falsos seus resultados comparados aos de verdadeira grandeza, pois os dispositivos com dimensões originais suportam até $15 \mathrm{MPa}$ sem qualquer alteração de sua estrutura e $10 \mathrm{MPa}$ com ampliação das descontinuidades. Já os dispositivos reduzidos apresentavam perda de adesão borracha-aço com $15 \mathrm{MPa}$, além do rasgamento do elastômero (SIQUEIRA; SILVA, 2009).

O problema maior está no instante em que o dispositivo deve ser retirado da estrutura para a colocação de um novo. Uma monitoração proporciona o acompanhamento, e estudos teóricos e práticos podem orientar quanto à necessidade de troca dos aparelhos de apoio, garantindo o bom funcionamento da estrutura (SIQUEIRA; SILVA, 2009).

O alto nível de complexidade para a substituição do aparelho de apoio é resultante do limitado espaço e acessibilidade para a execução do serviço, interdição e elevação, visto que pontes são usadas continuamente e não podem ser interditadas com grande frequência. Com base nas dificuldades e dos gastos derivados da substituição, foi estipulada uma tolerância para os antigos aparelhos de apoio, pois uma vez que as estruturas estão operando de forma isolada e seu desempenho não está sendo prejudicado por danos oriundos do dispositivo, a falta de trincas e fissuras na região do apoio poderão delongar a substituição mediante verificações estruturais e inspeção minuciosa. Segue o processo (MACHADO; SARTORTI, 2010):

- Inspeção visual nas faces acessíveis do aparelho de apoio;

- Aparelhos que em alguns anos de atividade apresentam pequenas fissuras de 2 a $3 \mathrm{~mm}$, tanto em profundidade quanto em cumprimento, são admissíveis; 
- Averiguar a correta vulcanização do aparelho de apoio, atentando para a visibilidade e oxidação das chapas de aço fretantes;

- Se a estrutura apresentar deslocamento, é preciso medir os ângulos entre as superfícies das estruturas em contato com o dispositivo;

- Medir as alturas nas arestas e nos pontos centrais do aparelho;

- Medir suas distorções;

- Verificar se houve deslocamento de sua posição inicial;

- Verificar a presença de substâncias nocivas ao elastômero;

- Averiguar se há juntas de dilatação defeituosas na superestrutura.

O DNER indica que a substituição deve ser em conformidade com o projeto executivo. Esse termo integra, quando necessário, o projeto de recuperação - projeto executivo de recuperação, sendo necessário desviar o tráfego antes de iniciar os serviços, só podendo regressar após a conclusão do mesmo. Para a substituição existem fatores e recomendações (MACHADO; SARTORTI, 2010):

- Operação de macaqueamento;

- Como obrigatoriedade, as juntas de dilatação devem estar limpas antes de iniciar os procedimentos de macaqueamento;

- É preciso liberar a estrutura dos aterros para substituir apoios extremos, removendo uma faixa do aterro de cabeceira com o consecutivo preenchimento do solo-cimento e consolidando com compactação manual;

- A laje de aproximação (transição) torna difícil a substituição, impedindo o acesso por estar ligando o tabuleiro ao terrapleno. Em casos como este, é necessário demolir a laje para possibilitar os procedimentos e reconstruir após finalizar o procedimento;

- À medida que a estrutura é tirada do apoio, têm de ser introduzidos calços ou equipamentos de autotravamento com o objetivo de evitar acidentes ocasionados por eventual perda de pressão;

- Posterior à substituição, a maneira de operação precisa ser inversa, com remoção gradual dos calços, redução lenta, uniforme e constante das pressões, até que a estrutura se posicione perfeitamente sobre os novos aparelhos de apoio.

\section{Conclusões}

O aparelho de apoio fretado de neoprene pode simplificar e otimizar estruturas, mantendo a estabilidade ao torná-la uma estrutura isostática e minorando a grandeza total da estrutura visando projetar estruturas mais econômicas. O projeto desse dispositivo corresponde com as normas usadas em projetos de estruturas, porém sua vida útil é menor do que a vida útil global da estrutura. Um dos fatores que mais contribui para isto é a sua incorreta instalação. Esses dispositivos são capazes de operar em vínculos que apresentam perda de capacidade portante e têm sido desenvolvidos com base em estudos que buscam dados de ensaios com o propósito de garantir melhorias na fabricação, no projeto, na aceitação e rejeição e ao determinar parâmetros técnicos que certifiquem sua substituição. É fundamental que se leve em consideração a esconsidade do aparelho de apoio com relação à instabilidade lateral de vigas prémoldadas e protendidas, que são assentadas sobre aparelhos de apoio fretado de neoprene quando estão em estágio de transição ou serviço. É necessário atentar para a importância da concessão de rodovia, apesar das críticas sobre pedágios nas rodovias privatizadas, diante da vantagem desse modelo de privatização instituir um programa de manutenção de pontes e viadutos. 
Rian de Oliveira Lan

\section{Referências}

ANDRADE, R. G.; TRAUTWEIN, L. M.; BITTENCOURT, T. N. Comparativo e calibração de modelos numéricos a partir de dados de monitoramento de uma ponte rodoviária curva de concreto armado. Revista IBRACON de Estruturas e Materiais, São Paulo, v. 9, n. 6, p. 121-138, 2013.

BRANCO, F. A.; PAULO, P. V. O projecto de pontes para vidas superiores a 100 anos. Revista ALCONPAT, [S. I.] v. 2, n.1, p. 1-9, 2012.

CARDOSO, M. T. S. A.; LIMA, M. C. V. Determinação numérica de rigidezes de almofada de apoio fretado em análise tridimensional no ANSYS. In: I SIMPÓSIO DE MÉTODOS NUMÉRICOS EM ENGENHARIA, 1. 2016, Anais [...], Curitiba, 2016. p. 46-51.

DIÓGENES, A. G.; BRANDÃO, F. S.; SANTOS, M. W. L. C.; BRAGA, W. A. Manifestações

patológicas em pontes da cidade de Sobral - CE. In: CONGRESO INTERNACIONAL SOBRE PATOLOGÍA Y RECUPERACIÓN DE ESTRUCTURAS, 10., 2014, Santiago. Anais [...]. Santiago: [s. n.], 2014. p. 2-9.

FANTE, F.; PRADO, F.; STUCCH, F.; TOALDO, G.; SKAF, K.; WAIMBERG, M.; MARQUESE, M. O caso do viaduto T5 na Marginal Pinheiros. Revista Estrutura, São Paulo, v. 8, p. 22-26, 2019.

FERNANDES, A. V.; CORREIA, V. C. Uma introdução ao estudo das pontes em viga. Ciências exatas e tecnológicas, Aracaju, v. 4, n. 1, p. 115-138, mar. 2017.

GOMES, C.; MONTEIRO, E.; VITÓRIO, A. Um estudo a degradação estrutural de pontes e viadutos rodoviários. In: CONGRESSO INTERNACIONAL SOBRE PATOLOGIA E REABILITAÇÃO DE ESTRUTURAS, 13., 2017, Crato. Anais [... ]. Crato: [s. n.] 2017. p. 67-82.

MACHADO, R. N.; SARTORTI, A. L. Pontes: patologias dos aparelhos de apoio. In: CONGRESO INTERNACIONAL SOBRE PATOLOGÍA Y RECUPERACIÓN DE ESTRUCTURAS, 6., 2010, Córdoba. Anais [...]. Córdoba: UTN, 2010.

NUERNBERG, R.; Silva, B. D. Estudo das possíveis causas do deslocamento longitudinal de vigas sobre aparelhos de apoio em viaduto da rodovia BR-101/SC. 2013. Trabalho de Conclusão de Curso (Bacharelado em Engenharia Civil) - Universidade do Extremo Sul Catarinense, Santa Catarina, 2013.

REIS, P. H. L. P.; ROCHA, P. M.; PEQUENO, R. M. D.; AMORIM, M. R. G.; PEREIRA, S. S. R. Análise comparativa entre esforços solicitantes atuantes em tabuleiros de pontes obtidos através das tabelas de Rüsch e elementos finitos. In: CONGRESSO BRASILEIRO DE PONTES E ESTRUTURAS, 10., 2018, Rio de Janeiro. Anais [... ] Rio de Janeiro: [s.n.], 2018.

ROLIM, P. S. W.; SILVA, A. B.; DE SOUZA, R. M.; SAMPAIO, R. A. C.; SILVA, E. M. L. Metodologia de análise estrutural e capacidade resistente de ponte em concreto armado. In: CONGRESSO BRASILEIRO DE PONTES E ESTRUTURAS, 5., 2012, Rio de janeiro. Anais [...]. Rio de Janeiro: [s.n.], 2012.

SANTOS, D. F.; SANTANA, T. L.; HONORATO, M. P.; COELHO, S. C.; VALARES, L. G.; GAMA, P. R. Estudo e análise das patologias da ponte de porto nacional - TO. Revista Engenharia Estudo e Pesquisa, Rio de Janeiro, v. 17, p. 31-41, 2017.

SANTOS, R. R.; OLIVEIRA, D. R. Vida útil à fadiga de uma ponte ferroviária na estrada de ferro Carajás, São Paulo, Revista IBRACON de Estruturas e Materiais, São Paulo, v. 5, n. 5, p. 627-658, out. 2012.

SILVA, A. C.; CAMPOS, G. R.; SANTOS FILHO, M. L. Análise de manifestações patológicas em obras de arte especiais - estudo de caso e propostas de recuperação. Revista Técnico-Científica do CREA-PR, Curitiba, p. 1-15, 2017. Edição especial. 
SILVA, E. C. V.; RODRIGUES NETO, E..; LIMA, F. B., MORAES, K. A. M. Análise de manifestações patológicas: um estudo de caso da ponte sobre a laguna de Roteiro-AL. In: CONGRESSO TÉCNICO DA ENGENHARIA E DA AGRONOMIA, 2018, Anais [...]. Maceió: [s. n.], 2018.

SIQUEIRA, C. H. Aparelhos de apoio e juntas de dilatação para pontes e viadutos: problemas e soluções. In: CONGRESSO INTERNACIONAL SOBRE PATOLOGIA E REABILITAÇÃO DE ESTRUTURAS, 5., 2009, Curitiba, Anais [...]. Curitiba: [s. n.], 2017.

SIQUEIRA, C. H. Medidas preventivas para manutenção de pontes. Revista IBRACON Concreto e Construções, São Paulo, n. 40, p. 69-75, 2012.

THOMAZ, E.; CARNEIRO, L.; SARAIVA, R. Vigas Gerber com dentes múltiplos: dimensionamento e detalhamento. In: CONGRESSO BRASILEIRO DE PONTES E ESTRUTURAS, 7., 2014, Rio de janeiro, Anais [...]. Rio de Janeiro: [s. n.], 2014.

VIEIRA, M. I. C. Tipologia, instalação, funcionamento e manutenção dos diversos tipos de aparelhos de apoio em obras de arte. 2013. Dissertação (Mestrado em Engenharia Civil) - Instituto Superior de Engenharia de Lisboa, Lisboa, 2013.

VIVAN, M. E. Aparelhos de apoio estruturais. Revista IBRACON Concreto e Construções, [S. I.], n. 7, p. 112-115, 2015.

\section{Sobre o autor}

Rian de Oliveira Lan

Graduação em Engenharia Civil pela Universidade Candido Mendes (2018). Atualmente é quotista e responsável técnico na Lan Engenharia Ltda. Tem experiência na área de engenharia estrutural.

Recebido em: 29.02.2020

Aceito em: 09.04.2020 